\title{
Tetramethylpyrazine reduces inflammation levels and the apoptosis of LPS-stimulated human periodontal ligament cells via the downregulation of miR-302b
}

\author{
YAN DUAN $^{1}$, WEI AN ${ }^{2}$, YUNXIA WU ${ }^{3}$ and JIN WANG ${ }^{4}$ \\ Departments of ${ }^{1}$ Oral Medicine and ${ }^{2}$ Oral Surgery, Shanxi Provincial People's Hospital, Taiyuan, Shanxi 030000; \\ ${ }^{3}$ Department of Oral Medicine, First Hospital of Shanxi Medical University, Taiyuan, Shanxi 030001; \\ ${ }^{4}$ Department of Oral and Maxillofacial Surgery, Jinan Stomatological Hospital, Jinan, Shandong 250000, P.R. China
}

Received December 6, 2019; Accepted March 12, 2020

DOI: $10.3892 / \mathrm{ijmm} .2020 .4554$

\begin{abstract}
Periodontitis is the main cause of tooth or tissue loss. Human periodontal ligament stem cells (hPDLSCs), which have high proliferative, self-renewal and multi-differentiation abilities, are vital for the restoration of periodontitis-induced injuries. The anti-inflammatory and anti-apoptotic agent, tetramethylpyrazine (TMP), is a promising agent used for the protection of PDLSCs from apoptosis and inflammation induced by periodontitis. The aim of the present study was to investigate the effects of TMP on lipopolysaccharide (LPS)-stimulated hPDLSCs. LPS-stimulated hPDLSCs were established as the cell model. CCK-8 assay was performed to evaluate cell viability, western blot analysis was performed to measure protein expression and flow cytometry was performed to detect cell apoptosis levels. Detection kits were used to evaluate the levels of tumor necrosis factor (TNF)- $\alpha$, interleukin (IL)-1 $\beta$ and IL-6. Reverse transcription-quantitative PCR analysis was performed to detect gene expression. TMP alleviated the effects of LPS on cell viability, inflammation levels and cell apoptosis. TMP downregulated microRNA (miR)-302b levels in LPS-stimulated cells. Transfection with miR-302b mimic reversed the anti-inflammatory and anti-apoptotic effects of TMP on LPS-stimulated cells. TMP reduced inflammation and the apoptosis of LPS-stimulated human periodontal ligament cells via the downregulation of miR-302b. The anti-inflammatory and anti-apoptotic effects exerted by TMP render it a promising agent for the protection of PDLSCs from injuries induced by periodontitis. The findings of the present study may aid in the development of a novel strategy for the treatment of periodontitis and may pave the way for further research.
\end{abstract}

Correspondence to: Dr Jin Wang, Department of Oral and Maxillofacial Surgery, Jinan Stomatological Hospital, 101 Jingliu Road, Jinan, Shandong 250000, P.R. China

E-mail: jinwangjn@163.com

Key words: tetramethylpyrazine, inflammation, cell apoptosis, microRNA-302b, human periodontal ligament stem cells

\section{Introduction}

Periodontitis, which has a high incidence rate, is a chronic inflammatory disease that results in tooth loss (1). Periodontitis is characterized by the loss of alveolar bone periodontal ligament and gingival tissue, and is caused by numerous factors, including poor dental hygiene, the deposition of bacterial plaque on the teeth, traumatic misalignment of the teeth and imbalances of the inflammatory and immune response $(2,3)$. In addition, periodontitis has been reported to be associated with a number of diseases, such as hypertension, chronic kidney disease and diabetes (4-7). Therefore, the treatment for periodontitis is vital for health. The current treatments for periodontitis include flap curettage, scaling and root planing procedures (8-10). However, the effects of the aforementioned methods can only control the development of periodontitis (10). At present, there is still no effective treatment for periodontitis, at least to the best of our knowledge.

As mesenchymal stem cells, periodontal ligament stem cells (PDLSCs) have been the focus of research in the field of restoration and regeneration $(11,12)$. Regeneration therapy based on mesenchymal stem cells has yielded promising results (13). PDLSCs have been reported to possess a high proliferative, self-renewal and multi-differentiation abilities (14-17). Following transplantation, PDLSCs are expected to generate new tissues or reconstruct damaged tissues. PDLSC damage is a critical factor behind tooth loss. In addition, elevated inflammation levels promote the progression of periodontitis $(18,19)$. Therefore, it is vital to control the inflammatory damage of PDLSCs for the restoration of tissue and to inhibit the progression of periodontitis.

Lipopolysaccharide (LPS), a major stimulator of inflammation, rapidly promotes the generation of pro-inflammatory cytokines or inflammatory mediators. Therefore, LPS has been widely used for the construction of experimental models of periodontitis (20). Studies have indicated that LPS levels are high in patients with periodontitis (21). LPS is a vital factor and LPS-stimulated cell models can provide a reference for clinical diagnosis and therapy. LPS-stimulated human periodontal ligament cells were constructed as a cell model in the present study. 
Chinese herbal monomers have exhibited improved anti-inflammatory abilities in numerous diseases (22-25). Tetramethylpyrazine (TMP), which is extracted from Ligusticum wallichii, has been used in cardiovascular disorders in clinical practice (26). LPS has been confirmed to possess numerous bioactivities, such as anti-inflammatory, anti-apoptotic and antioxidant effects (26). Furthermore, TMP has been reported to possess anti-inflammatory bioactivity in spinal cord ischemia-reperfusion injury, human umbilical vein endothelial cell inflammation injury and brain injury (27-30). However, the effects of TMP on periodontitis remain to be elucidated. The present study investigated the effects of TMP in LPS-stimulated human PDLSCs (hPDLSCs). The results revealed that TMP exerted anti-inflammatory and anti-apoptotic effects against LPS-stimulated hPDLSCs via the downregulation of microRNA (miR)-302b.

\section{Materials and methods}

Cells and cell culture. hPDLSCs (HUM-iCELL-m002; iCell Bioscience Inc.) were cultured at a density of $1 \times 10^{4}$ cells/well in DMEM (Gibco; Thermo Fisher Scientific, Inc.) containing $10 \% \mathrm{FBS}$ in $5 \% \mathrm{CO}_{2}$ at $37^{\circ} \mathrm{C}$.

CCK- 8 assay. To evaluate the effects of LPS on hPDLSCs, the cells were divided into the control group and LPS group. Cells were treated with $1 \mu \mathrm{g} / \mathrm{ml}$ LPS (Sigma-Aldrich; Merck KGaA). Subsequently, the cells were incubated for 24,48 and $72 \mathrm{~h}$, at $37^{\circ} \mathrm{C}$. To evaluate the effects of TMP on hPDLSCs, the cells were divided into the control and experimental groups. Cells in the experimental group were treated with various concentrations of TMP $(10,20$ and $30 \mu \mathrm{m})$ and incubated for 24,48 or $72 \mathrm{~h}$, at $37^{\circ} \mathrm{C}$. To investigate the effects of TMP on LPS-stimulated hPDLSCs, the cells were divided into the control and experimental groups. The cells in the experimental groups were treated with various concentrations $(10,20$ and $30 \mu \mathrm{m}$ ) of TMP (purity $\geq 98 \%$; Beijing Solarbio Science and Technology Co., Ltd.) in the presence of $1 \mu \mathrm{g} / \mathrm{ml}$ LPS. Following treatment, $10 \mu \mathrm{l} \mathrm{CCK}-8$ solution was added to each well and the cells were incubated at $37^{\circ} \mathrm{C}$ for $1 \mathrm{~h}$. Cell viability was determined by the reading the absorbance at a wavelength of $450 \mathrm{~nm}$ using a Varioskan ${ }^{\mathrm{TM}}$ LUX multimode microplate reader (Thermo Fisher Scientific, Inc.).

Assessment of inflammation levels. The inflammatory markers, tumor necrosis factor (TNF)- $\alpha$, interleukin (IL)-1 $\beta$ and IL-6, were evaluated. The cells were treated with $1 \mu \mathrm{g} / \mathrm{ml}$ LPS and various concentrations of TMP $(10,20$ and $30 \mu \mathrm{m})$. The experimental groups were treated with various concentrations of TMP in the presence of LPS. Cells treated with $1 \mu \mathrm{g} / \mathrm{ml}$ LPS were considered as the LPS group. Cells in the control, LPS and experimental groups were lysed with $0.25 \%$ trypsin and centrifuged at $16,000 \times \mathrm{g} 4^{\circ} \mathrm{C}$ for $15 \mathrm{~min}$ to harvest the supernatant. The levels of TNF- $\alpha$, IL-1 $\beta$ and IL- 6 in the supernatants were determined using the following ELISA kits: Human TNF- $\alpha$ (cat. no. ab181421; Abcam), human IL-1 $\beta$ (cat. no. ab100562; Abcam) and human IL-6 (cat. no. ab178013; Abcam).

Measurement of cell apoptosis. Following treatment, cells were digested with $0.25 \%$ trypsin and harvested. Cells were then rinsed with PBS (0.01 mol/l) and resuspended in binding buffer. A total of $1 \times 10^{6}$ cells were stained with Annexin V-FITC (5 $\mu \mathrm{l})$ and propidium iodide staining solution $(10 \mu \mathrm{l})$. The cell apoptosis of the different groups was analyzed using a flow cytometer (BD Biosciences).

Western blot analysis. Cells in each experimental group were lysed in lysis buffer (Beyotime). The protein concentration was measured using a bicinchoninic acid protein assay kit (Pierce; Thermo Fisher Scientific, Inc.). Total protein was separated by $10 \%$ SDS-PAGE. Separated proteins were then transferred to nitrocellulose membranes. Following blocking with skim milk, the membranes were incubated with primary antibodies against pro-caspase-3 (1:1,000; cat. no. ab32499; Abcam), Bax (1:200; cat. no. ab53154; Abcam), cleaved caspase-3 (1:1,000; cat. no. ab2302; Abcam), and Bcl-2 (1:500; cat. no. ab194583; Abcam) at $4{ }^{\circ} \mathrm{C}$ overnight. Subsequently, the membranes were incubated with horseradish peroxidase-labeled secondary antibody (1:2,000; Beyotime Institute of Biotechnology) for $1 \mathrm{~h}$, at room temperature. Protein bands were visualized using enhanced chemiluminescence reagent. Protein expression was determined using an ImageQuant LAS500 chemiluminescence camera (GE Healthcare Life Sciences) and ImageJ $1.52 \mathrm{k}$ software (National Institutes of Health).

Reverse transcription-quantitative PCR (RT-qPCR). miR-302b expression was measured using the RT-qPCR detection system (Applied Biosystems; Thermo Fisher Scientific, Inc.). Total RNA was extracted using TRIzol ${ }^{\circledR}$ reagent (Invitrogen; Thermo Fisher Scientific, Inc.) RNA was reverse transcribed into cDNA using a PrimeScript RT reagent kit (Takara Biotechnology Co., Ltd.). RT-qPCR analysis was performed as previously described (31).

Cell transfection. To verify the successful construction of the miR-302b mimic group, cells were divided into the control, miR-negative control (NC) and miR-302b mimic groups. The cells were transfected with $50 \mathrm{nmol} / \mathrm{l} \mathrm{miR-NC}$ and $50 \mathrm{nmol} / \mathrm{l}$ miR-302b mimic and incubated for $5 \mathrm{~min}$ at $37^{\circ} \mathrm{C}$. To investigate the effects of miR-302b mimic on inflammation and apoptosis, the cells were divided into the hPDLSC group, LPS group, LPS $(1 \mu \mathrm{g} / \mathrm{ml}$ for $72 \mathrm{~h})+$ TMP $(30 \mu \mathrm{m})$ group, LPS $(1 \mu \mathrm{g} / \mathrm{ml}$ for $72 \mathrm{~h})+$ TMP $(30 \mu \mathrm{m})+$ miR-NC group and LPS $(1 \mu \mathrm{g} / \mathrm{ml}$ for $72 \mathrm{~h})+\mathrm{TMP}(30 \mu \mathrm{m})+\mathrm{miR}-302 \mathrm{~b}$ mimic group.

Statistical analysis. Data are presented as the means \pm SD. Data analysis was performed using SPSS software (version no. 11.0; IBM Corp.) and GraphPad Prism (version no. 8.0; GraphPad Software, Inc.). One-way and two-way ANOVA were performed followed by Tukey's post hoc test for differential comparisons between groups.

\section{Results}

TMP alleviates the effects of LPS on cell viability. The concentrations of 10, 20 and $30 \mu \mathrm{m}$ TMP exerted no effect on cell viability, confirming that TMP had no toxic effect on the hPDLSCs (Fig. 1A). Following treatment with $1 \mu \mathrm{g} / \mathrm{ml}$ LPS for 48 and $72 \mathrm{~h}$, the cell survival rate was significantly lower compared with that of the control group, indicating that LPS exerted an inhibitory effect on cell viability (Fig. 1B). TMP 

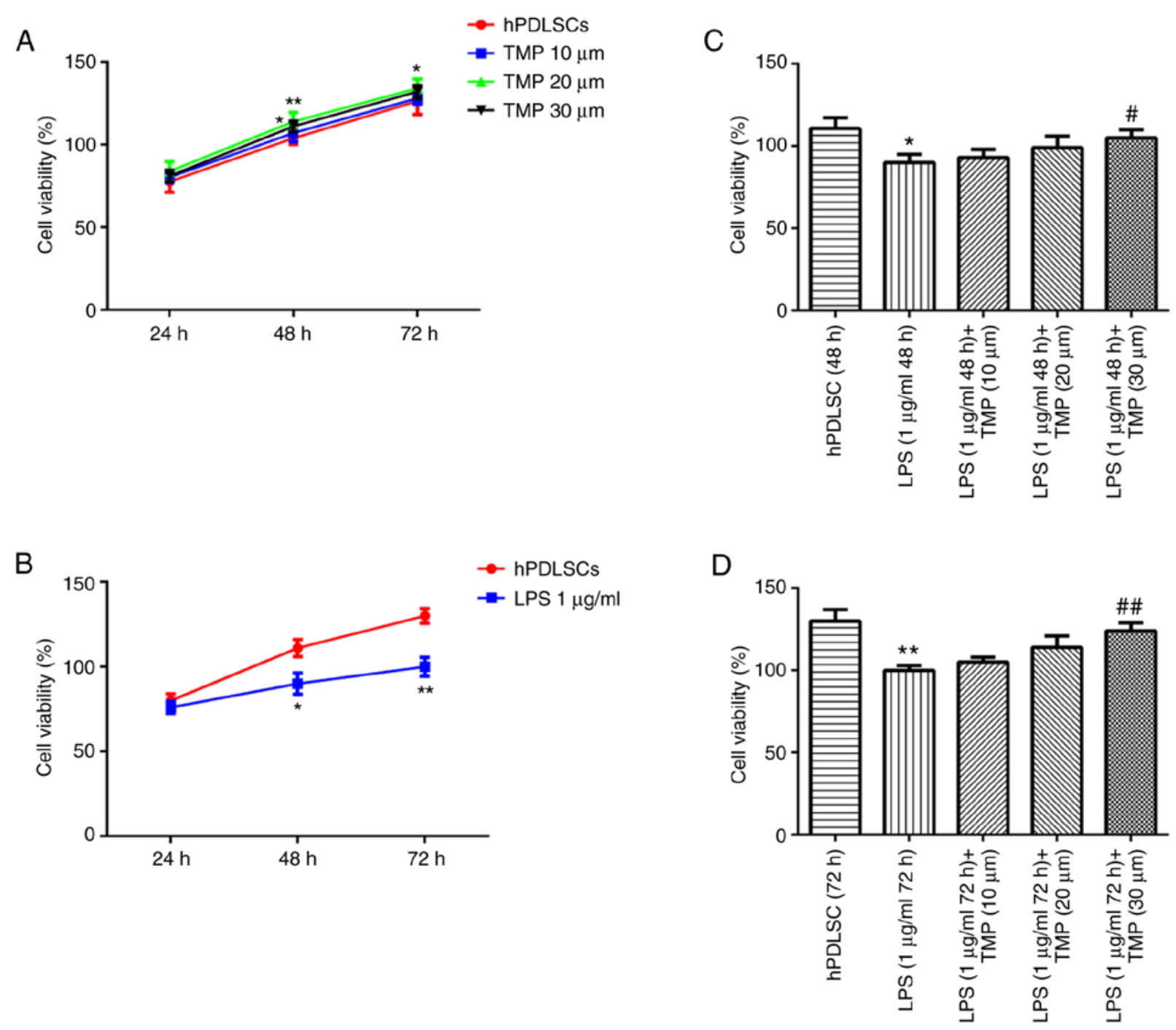

Figure 1. Effects of TMP tetramethylpyrazine on the viability of cells stimulated with LPS. (A and B) Cell viability at 24,48 and $72 \mathrm{~h}$ in the different groups. (C and D) Cell viability at 48 and $72 \mathrm{~h}$, respectively in the different groups. ${ }^{*} \mathrm{P}<0.05,{ }^{* *} \mathrm{P}<0.01 \mathrm{vs}$. hPDLSC group; ${ }^{*} \mathrm{P}<0.05,{ }^{\# \#} \mathrm{P}<0.01 \mathrm{vs}$. LPS $(1 \mu \mathrm{g} / \mathrm{ml})$ group. TMP, tetramethylpyrazine; LPS, lipopolysaccharide; hPDLSC, human periodontal ligament stem cell.
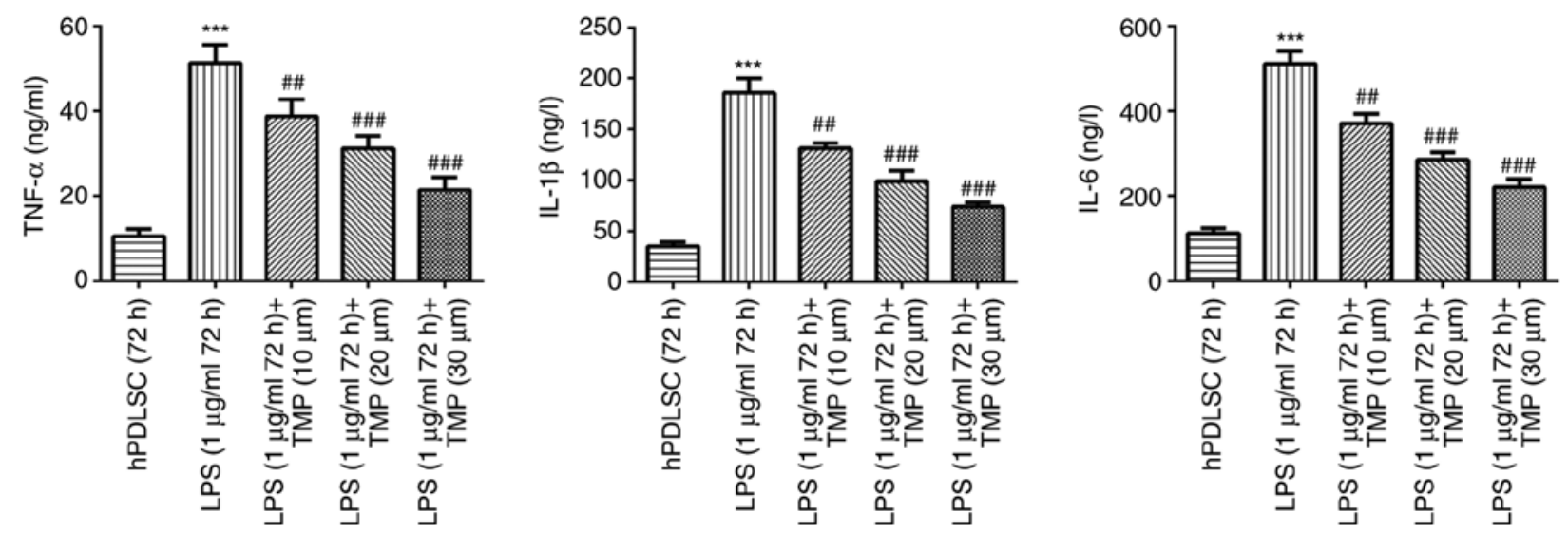

Figure 2. Effects of TMP on inflammation level in cells stimulated with LPS. Levels of TNF- $\alpha$, IL-1 $\beta$ and IL-6 in the different groups are shown. ${ }^{* * *} \mathrm{P}<0.001$ vs. hPDLSC group; ${ }^{\# \#} \mathrm{P}<0.01$ and ${ }^{\# \# \#} \mathrm{P}<0.001$ vs. LPS $(1 \mu \mathrm{g}, 72 \mathrm{~h})$. TMP, tetramethylpyrazine; LPS, lipopolysaccharide; hPDLSC, human periodontal ligament stem cell; TNF- $\alpha$, tumor necrosis factor $\alpha$; IL, interleukin.

treatment increased the survival rate of LPS-stimulated cells in a concentration-dependent manner (Fig. 1C and D).
TMP reduces the inflammation levels in LPS-stimulated hPDLSCs. Compared with the control group, TNF- $\alpha$, IL-1 $\beta$ 
A

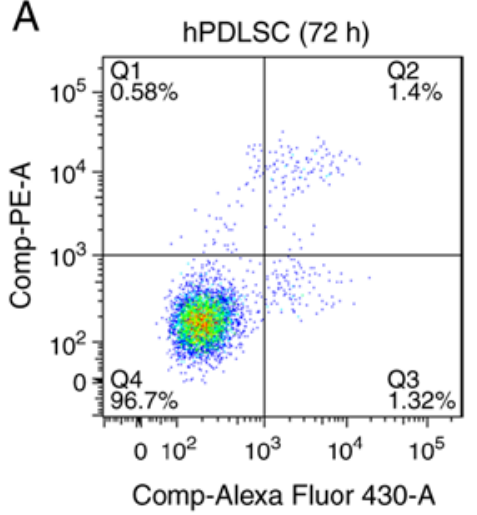

LPS $(1 \mu \mathrm{g} / \mathrm{ml} 72 \mathrm{~h})+$ TMP $(20 \mu \mathrm{m})$

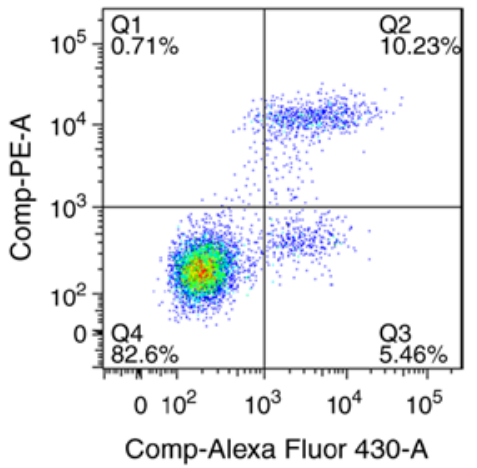

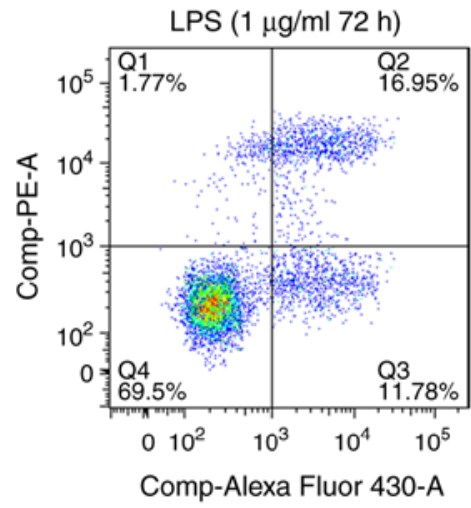

LPS $(1 \mu \mathrm{g} / \mathrm{ml} 72 \mathrm{~h})+$ TMP $(30 \mu \mathrm{m})$

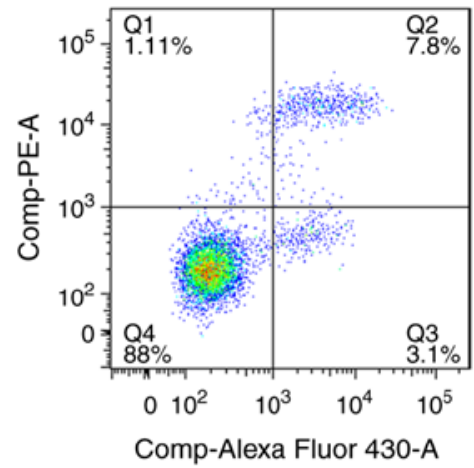

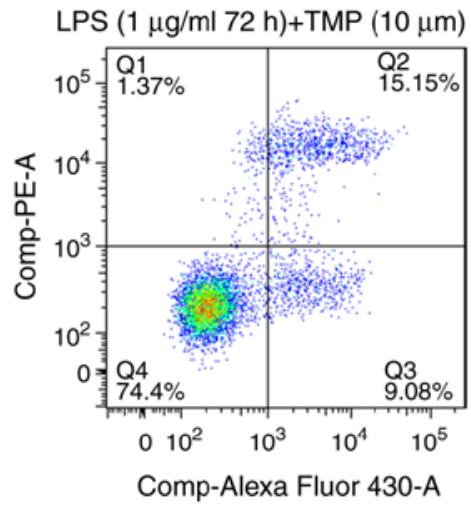

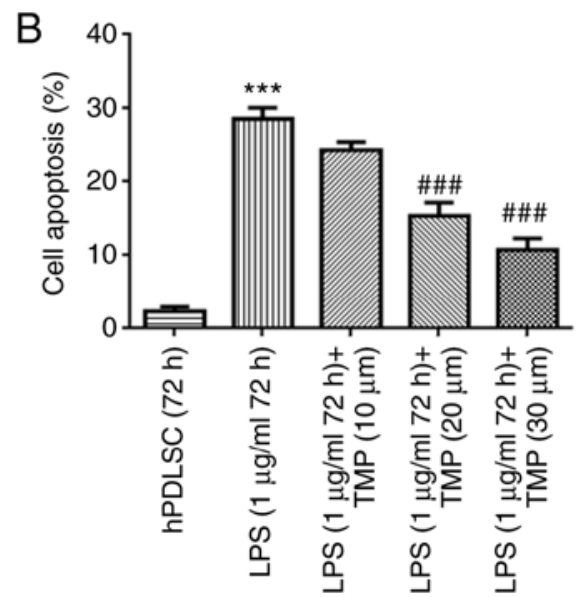

Figure 3. Effects of TMP on cell apoptosis induced by LPS. (A and B) Cell apoptotic level in the different groups. ${ }^{* * *} \mathrm{P}<0.001$ vs. hPDLSC group; ${ }^{\# \# \# ~} \mathrm{P}<0.001$ vs. LPS (1 $\mu \mathrm{g}, 72 \mathrm{~h}$ ) TMP, tetramethylpyrazine; LPS, lipopolysaccharide; hPDLSC, human periodontal ligament stem cell.
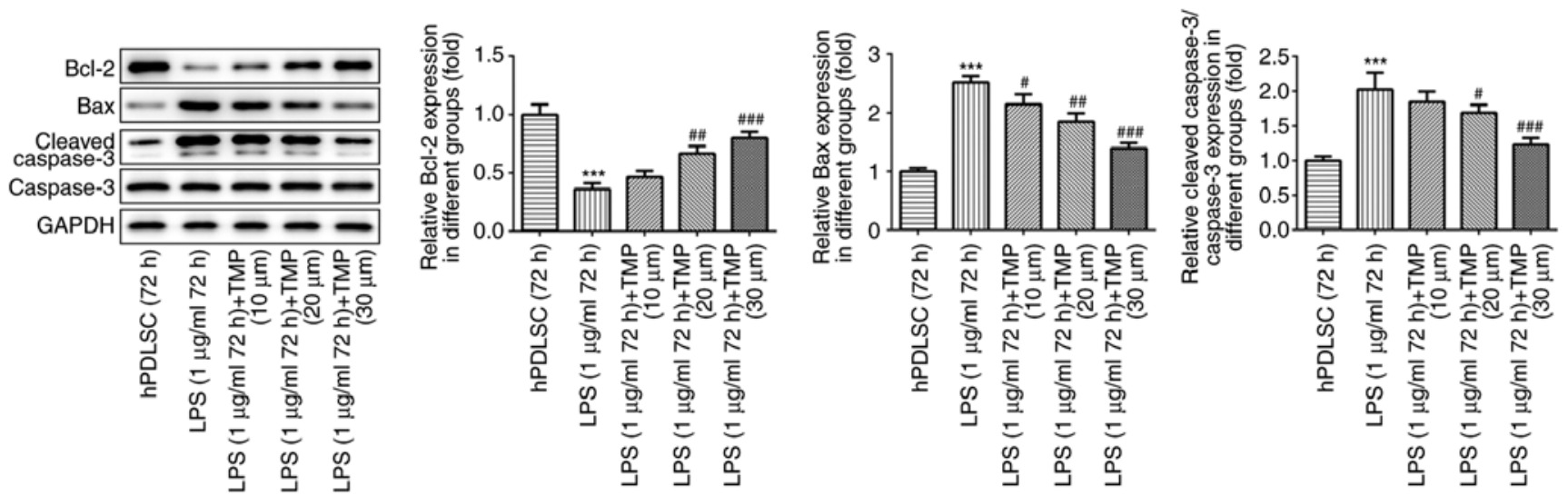

Figure 4. Effects of TMP on apoptosis-related proteins in cells stimulated with LPS. Expression levels of Bcl-2, Bax and cleaved caspase-3 in the different groups. ${ }^{* * *} \mathrm{P}<0.001$ vs. hPDLSC group; ${ }^{\#} \mathrm{P}<0.05,{ }^{\# \#} \mathrm{P}<0.01$ and ${ }^{\# \# \#} \mathrm{P}<0.001$ vs. LPS $(1 \mu \mathrm{g}, 72 \mathrm{~h})$. TMP, tetramethylpyrazine; LPS, lipopolysaccharide; hPDLSC, human periodontal ligament stem cell.

and IL-6 levels were increased following LPS treatment, confirming that the present cell model of periodontitis was successfully established. The inflammation levels induced by LPS were reduced by TMP treatment in a concentration-dependent manner (Fig. 2).

$T M P$ reduces the cell apoptosis of LPS-stimulated hPDLSCs. Cell apoptotic levels were evaluated by flow cytometry. Cell apoptosis was elevated in the LPS group compared with the control group (Fig. 3). TMP alleviated the apoptosis of LPS-stimulated hPDLSCs in a concentration-dependent manner. The expression of apoptosis-related proteins was also evaluated. Compared with the control group, the levels of the pro-apoptotic proteins, Bax and cleaved caspase-3, were upregulated, while the levels of the anti-apoptotic protein, Bcl-2, was decreased in the LPS-stimulated cells 


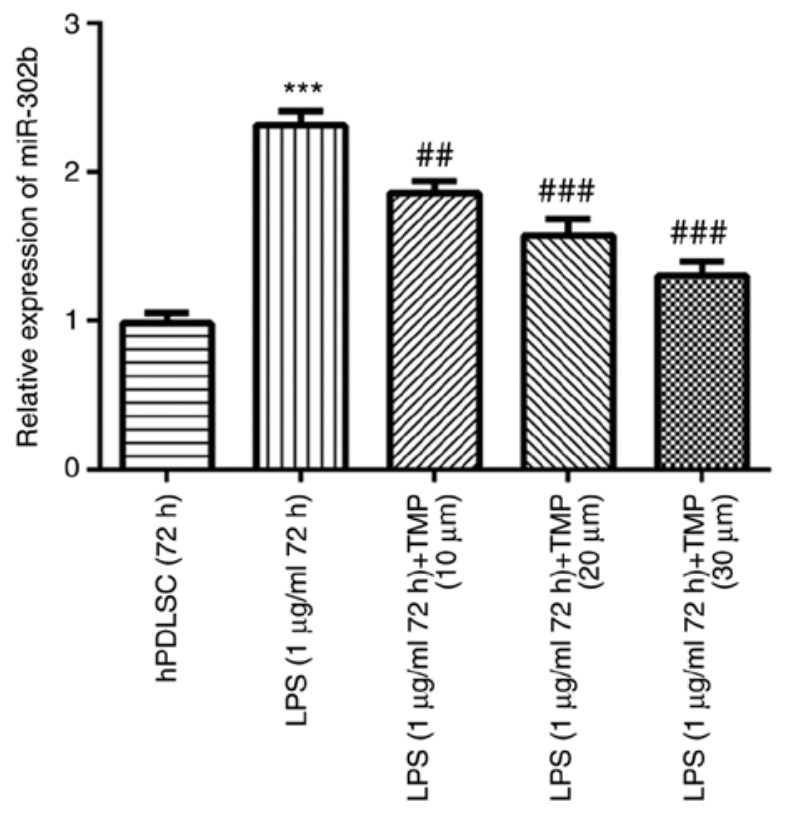

Figure 5. TMP inhibits the miR-302b expression level in LPS-stimulated cells. miRNA-302b expression level in the different groups. ${ }^{* * *} \mathrm{P}<0.001$ vs. hPDLSC group; ${ }^{\#} \mathrm{P}<0.01$ and ${ }^{\# \#} \mathrm{P}<0.001$ vs. LPS $(1 \mu \mathrm{g}, 72 \mathrm{~h})$. TMP, tetramethylpyrazine; LPS, lipopolysaccharide; hPDLSC, human periodontal ligament stem cell.
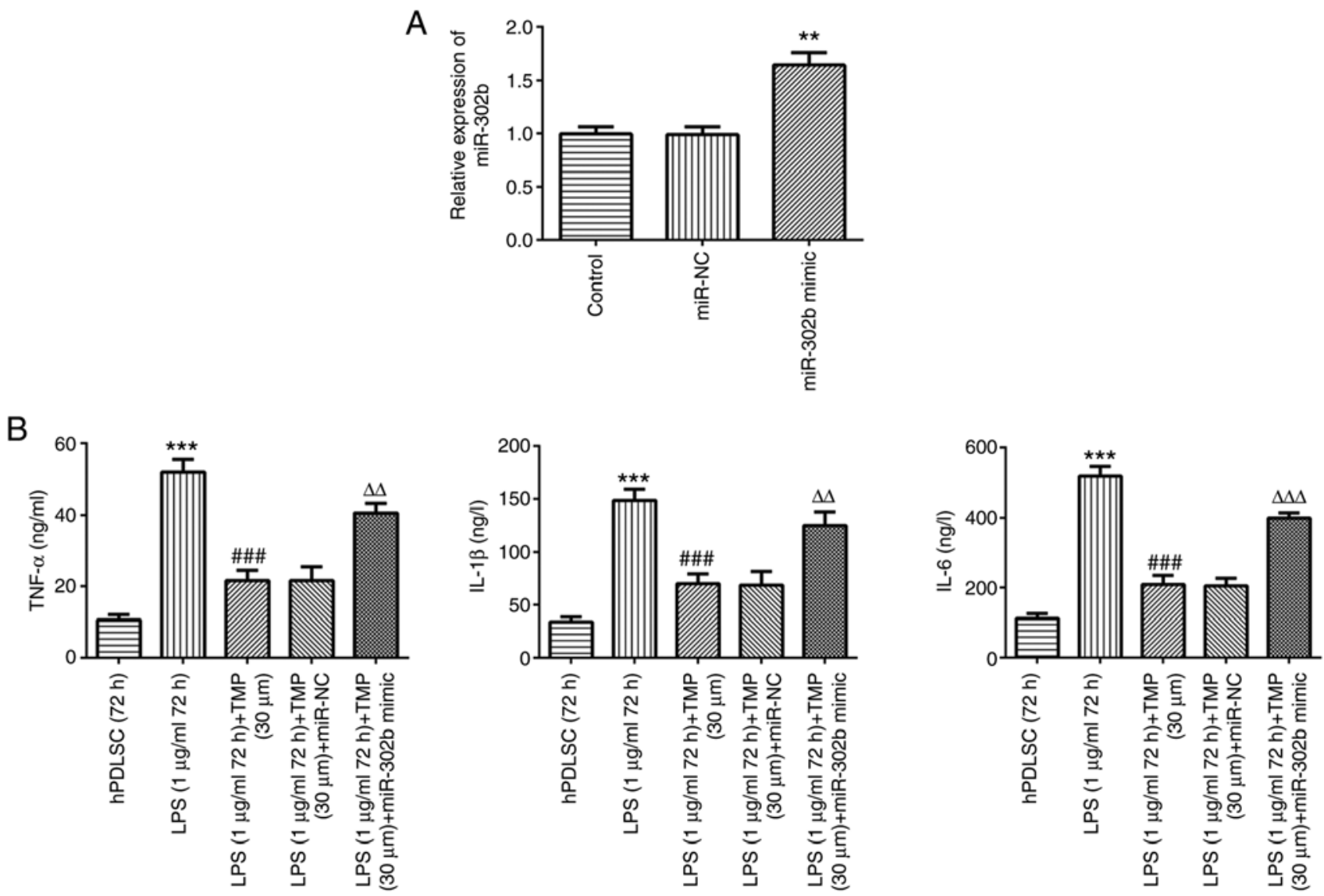

Figure 6. miR-302b overexpression blocks the anti-inflammatory effect of TMP on LPS-stimulated cells. (A) miR-302b expression level in the different groups. (B) Levels of TNF- $\alpha$, IL-1 $\beta$ and IL-6 in the different groups. ${ }^{* *} \mathrm{P}<0.01$ vs. miR-NC group; ${ }^{* * *} \mathrm{P}<0.001$ vs. hPDLSC group; ${ }^{\# \# \# ~} \mathrm{P}<0.001 \mathrm{vs}$. LPS $(1 \mu \mathrm{g}$, $72 \mathrm{~h}),{ }^{\Delta \Delta} \mathrm{P}<0.01$ and ${ }^{\Delta \Delta \Delta} \mathrm{P}<0.001$ vs. LPS $(1 \mu \mathrm{g}, 72 \mathrm{~h})+\mathrm{TMP}(30 \mu \mathrm{m})+$ miRNA-NC. TMP, tetramethylpyrazine; LPS, lipopolysaccharide; hPDLSC, human periodontal ligament stem cell; TNF- $\alpha$, tumor necrosis factor $\alpha$; IL, interleukin.

(Fig. 4). Following treatment with TMP, the Bax and cleaved caspase-3 levels decreased, and the Bcl-2 levels increased in a concentration-dependent manner in the LPS-stimulated cells. This indicated that TMP exerted protective effects on cell 
A
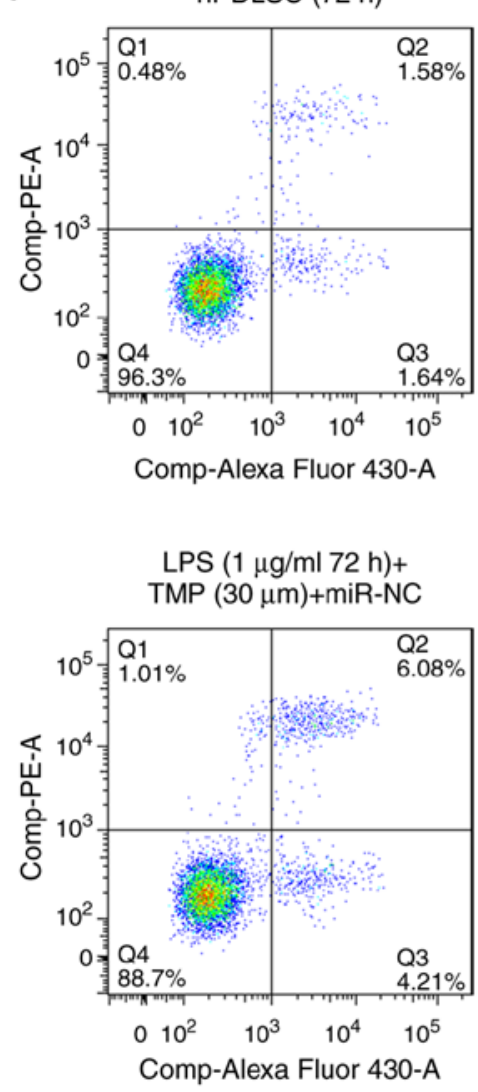

LPS $(1 \mu \mathrm{g} / \mathrm{ml} 72 \mathrm{~h})$

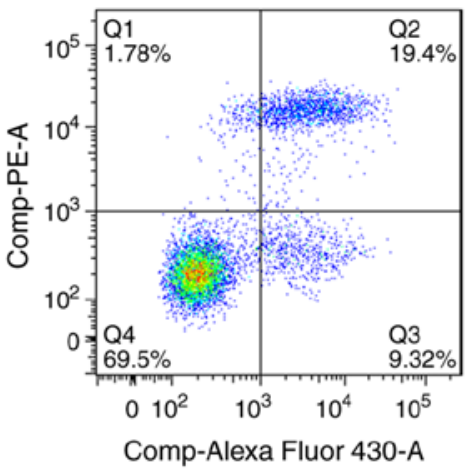

LPS $(1 \mu \mathrm{g} / \mathrm{ml} 72 \mathrm{~h})+\mathrm{TMP}(30 \mu \mathrm{m})+$ miR-302b mimic

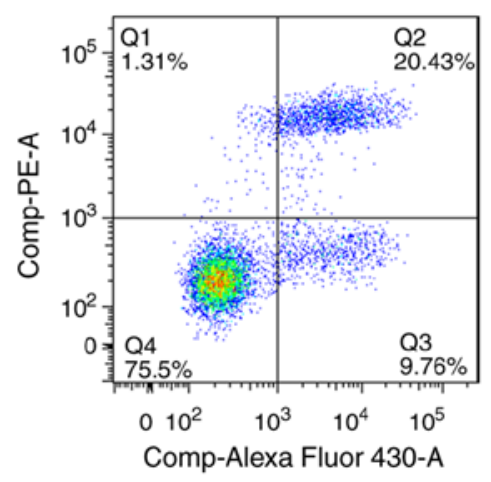

LPS $(1 \mu \mathrm{g} / \mathrm{ml} 72 \mathrm{~h})+\mathrm{TMP}(30 \mu \mathrm{m})$
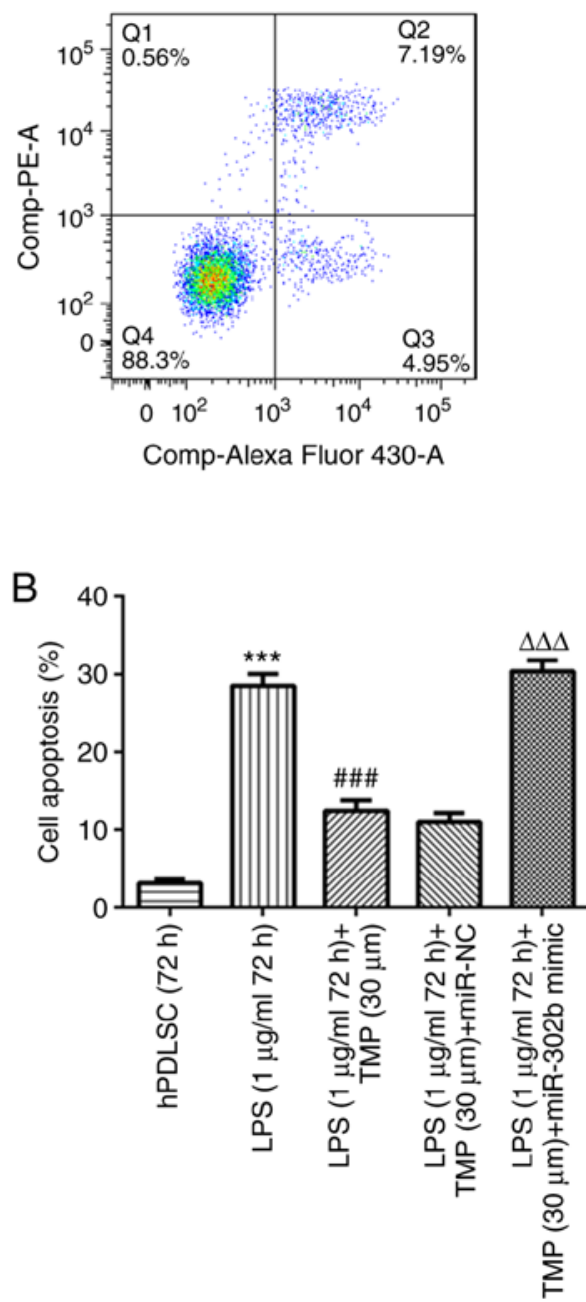

Figure 7. miR-302b overexpression blocks the anti-apoptotic effect of TMP on LPS-stimulated cells. (A and B) Cell apoptosis level in the different groups. ${ }^{* * * *} \mathrm{P}<0.001$ vs. hPDLSC group; ${ }^{\# \# "} \mathrm{P}<0.001$ vs. LPS $(1 \mu \mathrm{g}, 72 \mathrm{~h}),{ }^{\Delta \Delta \Delta} \mathrm{P}<0.001$ vs. LPS $(1 \mu \mathrm{g}, 72 \mathrm{~h})+\mathrm{TMP}(30 \mu \mathrm{m})+$ miRNA-NC. TMP, tetramethylpyrazine; LPS, lipopolysaccharide; hPDLSC, human periodontal ligament stem cell.
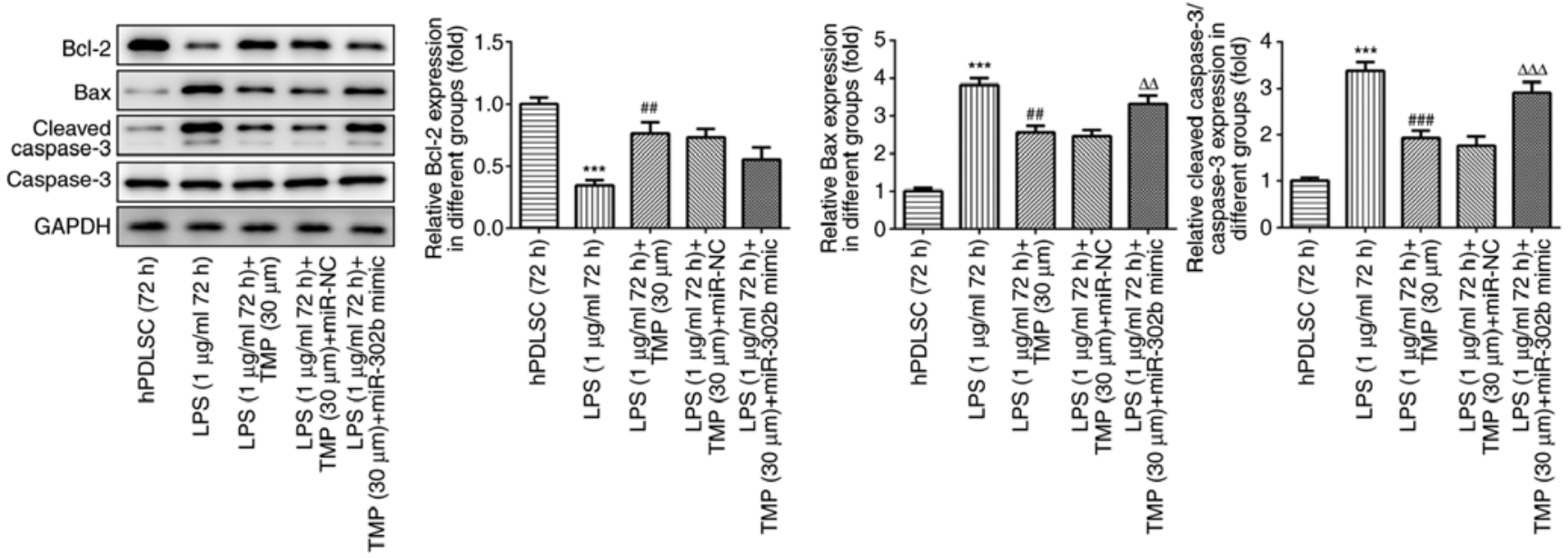

Figure 8. miR-302b overexpression reverses the effect of TMP on the expression levels of apoptosis-related proteins in LPS-stimulated cells. Expression levels of Bcl-2, Bax and cleaved caspase- 3 in the different groups. ${ }^{* * * *} \mathrm{P}<0.001$ vs. hPDLSC group; ${ }^{\# \#} \mathrm{P}<0.01$ and ${ }^{\# \# \#} \mathrm{P}<0.001 \mathrm{vs}$. LPS $(1 \mu \mathrm{g}, 72 \mathrm{~h}),{ }^{\Delta \wedge} \mathrm{P}<0.01$ and ${ }^{\Delta \Delta \Delta} \mathrm{P}<0.001 \mathrm{~s}$. LPS $(1 \mu \mathrm{g}, 72 \mathrm{~h})+\mathrm{TMP}(30 \mu \mathrm{m})+$ miRNA-NC.

apoptosis induced by LPS via the downregulation of Bax and cleaved caspase-3, and the upregulation of Bcl-2.
$T M P$ downregulates the miR-302b levels in LPS-stimulated cells. Compared with the control group, the miR-302b levels 
were upregulated in the LPS group. The miR-302b levels were downregulated by TMP in the LPS-stimulated cells in a concentration-dependent manner, indicating that miR-302b may play a role in LPS-induced injury and is a potential target of TMP (Fig. 5).

miR-302b mimic reverses the anti-inflammatory effects of TMP in LPS-stimulated cells. As shown in Fig. 6A, the miR-302b levels were higher compared with those in the control and miRNA-NC groups, indicating that miR-302b mimic was successfully transfected. LPS stimulation increased the levels of TNF- $\alpha$, IL- $1 \beta$ and IL- 6 compared with the controls, and this effect was reversed by TMP in a concentration-dependent manner (Fig. 6B). Following transfection with miR-302b mimic, inflammation levels increased in the LPS-stimulated cells compared with the LPS $(1 \mu \mathrm{g} / \mathrm{ml} 72 \mathrm{~h})+$ TMP $(30 \mu \mathrm{m})$ group, indicating that the anti-inflammatory effect of TMP in LPS-stimulated cells was achieved via the downregulation of miR-302b.

miR-302b mimic reverses the anti-apoptotic effects of TMP in LPS-stimulated cells. Cell apoptotic levels were higher in the LPS group compared with the control group (Fig. 7). LPS-induced cell apoptosis was reduced by TMP and this effect was weakened by miR-302b mimic transfection, indicating that the anti-apoptotic effect of TMP was achieved via the downregulation of miRNA-302b. The levels of the pro-apoptotic proteins, Bax and cleaved caspase-3, were elevated by LPS stimulation and the levels of the anti-apoptotic protein, Bcl-2, were decreased by LPS stimulation (Fig. 8). The effect induced by LPS was reversed by TMP. In addition, compared with the LPS $(1 \mu \mathrm{g} / \mathrm{ml}, 72 \mathrm{~h})+$ TMP $(30 \mu \mathrm{m})$ group, the levels of pro-apoptotic proteins increased, while those of Bcl-2 were downregulated in the LPS $(1 \mu \mathrm{g} / \mathrm{ml}, 72 \mathrm{~h})$ + TMP $(30 \mu \mathrm{m})+$ miR-302b mimic group, demonstrating that the anti-apoptotic effect of TMP was reversed by miR-302b mimic. The results revealed that the anti-apoptotic effect of TMP on the LPS-stimulated cells was achieved via the downregulation of miR-302b mimic.

\section{Discussion}

Periodontitis is a chronic disease that results in the loss of alveolar bone periodontal ligament and gingival tissue. Considering the poor microorganism sessile growth and biofilm penetration by biocides or antibiotics, current drug therapies, such as biocides or antibiotics are not ideal (32). Based on the high-proliferation, self-renewal and multi-differentiation abilities of PDLSCs, PDLSCs are vital for tissue restoration induced by periodontitis (17). Therefore the discovery of a novel a drug that can protect PDLSCs from apoptosis and inflammation-related injury is vital. The present study used LPS as the inflammation stimulator for the construction of the cell injury model.

The results of the present study demonstrated that the inflammation levels induced by LPS were higher, and this finding is consistent with those of previous studies (33-35). Previous studies have demonstrated that cell proliferation increases under inflammatory conditions $(36,37)$. In the present study, although the inflammation level was increased, the cell proliferation was decreased. This may be due to the different concentration and LPS-induced inflammation exposure time used from the previous study. The effects of inflammation on cell proliferation need to be further elucidated in future research.

The results of the present study demonstrated that TMP is a promising Chinese medicine monomer that protects PDLSCs from apoptosis and inflammation injury. Firstly, the cytotoxicity of TMP was evaluated. The present data indicated that treatment with $30 \mu \mathrm{m}$ TMP had no effect on cell survival. A previous study indicated that treatment with $400 \mu \mathrm{m}$ TMP exerted no toxic effects on PC12 cells and exerted protective effects against neurotoxicity (38).

Subsequently, the effects of LPS on PDLSCs were investigated. The results revealed that stimulation with $1 \mu \mathrm{g} / \mathrm{ml}$ LPS for $24 \mathrm{~h}$ significantly inhibited cell viability. Previous studies have demonstrated that TMP exerts anti-inflammatory effects on hepatic stellate cells, a mouse model of Parkinson's disease and myocardial cells (39-41). The present study demonstrated that inflammation levels induced by LPS were significantly reduced by TMP in a concentration-dependent manner.

Previous studies have demonstrated that TMP exerts an inhibitory effect on cell apoptosis in numerous cells, such as vascular endothelial cells, HepG2 cells, myocardial cells and bone marrow-derived mesenchymal stem cells (42-45). In the present study, cell apoptotic levels induced by LPS were markedly decreased by TMP in a concentration-dependent manner. In addition, the expression levels of apoptotic proteins were investigated as further evidence. The expression of the anti-apoptotic protein, Bcl-2, was decreased, and the levels of the pro-apoptotic proteins, Bax and cleaved caspase-3, were elevated in the LPS-stimulated PDLSCs. The aforementioned effects induced by LPS in the cells were all reversed by TMP. The results demonstrated that TMP is a promising agent for use in protecting PDLSCs from apoptosis and inflammation-related injury.

The mechanisms of action of TMP were also investigated in the present study. miRNAs have been confirmed as vital biomarkers in a number of diseases and regulate protein expression at the post-transcriptional level. miR-302b overexpression was confirmed to enhance the effects of LPS on apoptosis, inflammation and cell viability (46). In the present study, the miR-302b levels were elevated in the LPS-stimulated PDLSCs and were downregulated by TMP in a concentration-dependent manner. The present study further investigated whether miR-302b overexpression exerts effects on the LPS + TMP-treated cells. The results revealed that the anti-inflammatory and anti-apoptotic effects of TMP in the LPS-stimulated cells were inhibited by miR-302b overexpression. The results demonstrated that the anti-inflammatory and anti-apoptotic effects of TMP on LPS-induced cells was achieved via the downregulation of miR-302b.

In addition, since inflammation exerts negative effects on the multi-lineage differentiation potential and self-renewal capability of PDLSCs, the inflammatory response needs to be inhibited and the osteogenic differentiation of PDLSCs in the inflammatory microenvironment needs to be improved when periodontal tissue engineering is applied to repair alveolar bone defects. Therefore, further experiments are 
required to confirm the effects of TMP on multi-lineage differentiation.

To conclude, the present study found that TMP, with its anti-inflammatory and anti-apoptotic effects, may be a promising agent for use in protecting PDLSCs from periodontitis-induced injury. TMP is expected to be a novel agent for use in the treatment of periodontitis, while further research is still required to confirm the effects of TMP in vivo.

\section{Acknowledgements}

Not applicable.

\section{Funding}

No funding was received.

\section{Availability of data and materials}

The analyzed data sets generated during the present study are available from the corresponding author on reasonable request.

\section{Authors' contributions}

The first author YD prepared the manuscript, and was involved in all the experiments and analyzed the data. WA was involved in the cell experiments, as well as in the literature search and figure preparation. YW was involved in some sample preparations and literature searches. JW was involved in the communication with the journal during the manuscript submission and peer review and also contributed to the conception and design of the study. The present study was designed by YD and WA with the guidance of JW. All authors read and approved the final version of the manuscript.

\section{Ethics approval and consent to participate}

Not applicable.

\section{Patient consent for publication}

Not applicable.

\section{Competing interests}

The authors declare that they have no competing interests.

\section{References}

1. Serrano C and Suarez E: Prevalence of severe periodontitis in a colombian adult population. J Int Acad Periodontol 21: 53-62, 2019.

2. Zhang J, Zhang AM, Zhang ZM, Jia JL, Sui XX, Yu LR and Liu HT: Efficacy of combined orthodontic-periodontic treatment for patients with periodontitis and its effect on inflammatory cytokines: A comparative study. Am J Orthod Dentofacial Orthop 152: 494-500, 2017.

3. Ahmad N, Ahmad FJ, Bedi S, Sharma S, Umar S and Ansari MA: A novel nanoformulation development of eugenol and their treatment in inflammation and periodontitis. Saudi Pharm J 27: 778-790, 2019.
4. Czesnikiewicz-Guzik M, Osmenda G, Siedlinski M, Nosalski R, Pelka P, Nowakowski D, Wilk G, Mikolajczyk TP, Schramm-Luc A, Furtak A, et al: Causal association between periodontitis and hypertension: Evidence from mendelian randomization and a randomized controlled trial of non-surgical periodontal therapy. Eur Heart J 40: 3459-3470, 2019.

5. Wallace K, Shafique S and Piamjariyakul U: The relationship between oral health and hemodialysis treatment among adults with chronic kidney disease: A systematic review. Nephrol Nurs J 46: 375-394, 2019.

6. Zhou X, Zhang W, Liu X, Zhang W and Li Y: Interrelationship between diabetes and periodontitis: Role of hyperlipidemia. Arch Oral Biol 60: 667-674, 2015.

7. Franca LFC, Vasconcelos ACCG, da Silva FRP, Alves EHP, Carvalho JS, Lenardo DD, de Souza LKM, Barbosa ALR, Medeiros JR, de Oliveira JS and Vasconcelos DFP: Periodontitis changes renal structures by oxidative stress and lipid peroxidation. J Clin Periodontol 44: 568-576, 2017.

8. Trikka D and Vassilopoulos S: Periodontal regeneration with enamel matrix derivative in the management of generalized aggressive periodontitis: A case report with 11-year follow-up and literature review. J Int Soc Prev Community Dent 9: 13-20, 2019.

9. Bella P and Istvan G: The comprehensive periodontal, resorative end prosthodontic therapy of chronic periodontitis case presentation. Fogorv Sz 109: 125-135, 2016 (In English, Hungarian).

10. Ashouri Moghaddam A, Radafshar G, Jahandideh Y and Kakaei N: Clinical evaluation of effects of local application of aloe vera gel as an adjunct to scaling and root planning in patients with chronic periodontitis. J Dent (Shiraz) 18: 165-172, 2017.

11. Portron S, Soueidan A, Marsden AC, Rakic M, Verner C, Weiss P, Badran Z and Struillou X: Periodontal regenerative medicine using mesenchymal stem cells and biomaterials: A systematic review of pre-clinical studies. Dent Mater J 38: 867-883, 2019.

12. Son H, Jeon M, Choi HJ, Lee HS, Kim IH, Kang CM and Song JS: Decellularized human periodontal ligament for periodontium regeneration. PLoS One 14: e0221236, 2019.

13. Liu J, Yu F, Sun Y, Jiang B, Zhang W, Yang J, Xu GT, Liang A and Liu S: Concise reviews: Characteristics and potential applications of human dental tissue-derived mesenchymal stem cells. Stem Cells 33: 627-638, 2015.

14. Nagata M, Iwasaki K, Akazawa K, Komaki M, Yokoyama N, Izumi Y and Morita I: Conditioned medium from periodontal ligament stem cells enhances periodontal regeneration. Tissue Eng Part A 23: 367-377, 2017.

15. Zheng DH, Wang XX, Ma D, Zhang LN, Qiao QF and Zhang J: Erythropoietin enhances osteogenic differentiation of human periodontal ligament stem cells via Wnt/ $\beta$-catenin signaling pathway. Drug Des Devel Ther 13: 2543-2552, 2019.

16. Gu K, Fu X, Tian H, Zhang Y, Li A, Wang Y, Wen Y and Gu W: TAZ promotes the proliferation and osteogenic differentiation of human periodontal ligament stem cells via the p-SMAD3. J Cell Biochem 121: 1101-1113, 2020.

17. Menicanin D, Mrozik KM, Wada N, Marino V, Shi S, Bartold PM and Gronthos S: Periodontal-ligament-derived stem cells exhibit the capacity for long-term survival, self-renewal, and regeneration of multiple tissue types in vivo. Stem Cells Dev 23: 1001-1011, 2014

18. Li J, Li Y, Pan S, Zhang L, He L and Niu Y: Paeonol attenuates ligation-induced periodontitis in rats by inhibiting osteoclastogenesis via regulating $\mathrm{Nrf} 2 / \mathrm{NF}-\kappa \mathrm{B} / \mathrm{NFATc} 1$ signaling pathway. Biochimie 156: 129-137, 2019.

19. Zhou W, Su L, Duan X, Chen X, Hays A, Upadhyayula S, Shivde J, Wang H, Li Y, Huang D and Liang S: MicroRNA-21 down-regulates inflammation and inhibits periodontitis. Mol Immunol 101: 608-614, 2018

20. Elburki MS, Rossa C Jr, Guimarães-Stabili MR, Lee HM, Curylofo-Zotti FA, Johnson F and Golub LM: A chemically modified curcumin (CMC 2.24) inhibits nuclear factor $\kappa \mathrm{B}$ activation and inflammatory bone loss in murine models of LPS-induced experimental periodontitis and diabetes-associated natural periodontitis. Inflammation 40: 1436-1449, 2017.

21. Li F and Xu HS: Effects of low level laser combined with basic periodontal therapy on cytokines and LPS, leptin in gingival crevicular fluid of diabetes mellitus complicated with chronic periodontitis patients. Shanghai Kou Qiang Yi Xue 27: 637-640, 2018 (In Chinese). 
22. Wei S, Chi J, Zhou M, Li R, Li Y, Luo J and Kong L: Anti-inflammatory lindenane sesquiterpeniods and dimers from Sarcandra glabra and its upregulating AKT/Nrf2/HO-1 signaling mechanism. Industrial Crops and Products 137: 367-376, 2019.

23. Zhou J, Xu G, Yan J, Li K, Bai Z, Cheng W and Huang K: Rehmannia glutinosa (Gaertn.) DC. polysaccharide ameliorates hyperglycemia, hyperlipemia and vascular inflammation in streptozotocin-induced diabetic mice. J Ethnopharmacol 164: 229-238, 2015.

24. Chen X, Yi L, Song S, Wang L, Liang Q, Wang Y, Wu Y and Gao Q: Puerarin attenuates palmitate-induced mitochondrial dysfunction, impaired mitophagy and inflammation in L6 myotubes. Life Sci 206: 84-92, 2018.

25. Dong J, Liang W, Wang T, Sui J, Wang J, Deng Z and Chen D: Saponins regulate intestinal inflammation in colon cancer and IBD. Pharmacol Res 144: 66-72, 2019.

26. Michel HE and Menze ET: Tetramethylpyrazine guards against cisplatin-induced nephrotoxicity in rats through inhibiting HMGB1/TLR4/NF- $\kappa \mathrm{B}$ and activating Nrf2 and PPAR- $\gamma$ signaling pathways. Eur J Pharmacol 857: 172422, 2019.

27. Fan L, Wang K, Shi Z, Die J, Wang C and Dang X Tetramethylpyrazine protects spinal cord and reduces inflammation in a rat model of spinal cord ischemia-reperfusion injury. J Vasc Surg 54: 192-200, 2011

28. Chen J, Wang H, Gao C, Liu D, Fan Y, Li W, Chen Y and Pan S: Tetramethylpyrazine alleviates LPS-induced inflammatory injury in HUVECs by inhibiting Rho/ROCK pathway. Biochem Biophys Res Commun 514: 329-335, 2019.

29. Kao TK, Chang CY, Ou YC, Chen WY, Kuan YH, Pan HC, Liao SL, Li GZ and Chen CJ: Tetramethylpyrazine reduces cellular inflammatory response following permanent focal cerebral ischemia in rats. Exp Neurol 247: 188-201, 2013.

30. Liao SL, Kao TK, Chen WY, Lin YS, Chen SY, Raung SL, $\mathrm{Wu} \mathrm{CW}, \mathrm{Lu} \mathrm{HC}$ and Chen CJ: Tetramethylpyrazine reduces ischemic brain injury in rats. Neurosci Lett 372: 40-45, 2004

31. Ge T, Yin M, Yang M, Liu T and Lou G: MicroRNA-302b suppresses human epithelial ovarian cancer cell growth by targeting RUNX1. Cell Physiol Biochem 34: 2209-2220, 2014.

32. Lazar V, Saviuc CM and Chifiriuc MC: Periodontitis and periodontal disease-innovative strategies for reversing the chronic infectious and inflammatory condition by natural products. Curr Pharm Des 22: 230-237, 2016.

33. Jia R, Yi Y, Liu J, Pei D, Hu B, Hao H, Wu L, Wang Z, Luo X and $\mathrm{Lu}$ Y: Cyclic compression emerged dual effects on the osteogenic and osteoclastic status of LPS-induced inflammatory human periodontal ligament cells according to loading force. BMC Oral Health 20: 7, 2020.

34. Duan Y, An W, Wu H and Wu Y: Salvianolic acid C attenuates LPS-induced inflammation and apoptosis in human periodontal ligament stem cells via toll-like receptors 4 (TLR4)/nuclear factor kappa B (NF-кB) pathway. Med Sci Monit 25: 9499-9508, 2019.

35. Wang L, Xia J, Liu Q and Jin Y: Effect of lipopolysaccharide on proliferation and inflammatory factors expression of human periodontal ligament stem cells. Hua Xi Kou Qiang Yi Xue Za Zhi 31: 286-290, 2013 (In Chinese).
36. Yu Y, Bi CS, Wu RX, Yin Y, Zhang XY, Lan PH and Chen FM: Effects of short-term inflammatory and/or hypoxic pretreatments on periodontal ligament stem cells: In vitro and in vivo studies. Cell Tissue Res 366: 311-328, 2016.

37. Tang HN, Xia Y, Yu Y, Wu RX, Gao LN and Chen FM: Stem cells derived from 'inflamed' and healthy periodontal ligament tissues and their sheet functionalities: A patient-matched comparison. J Clin Periodontol 43: 72-84, 2016.

38. Guan D, Su Y, Li Y, Wu C, Meng Y, Peng X and Cui Y: Tetramethylpyrazine inhibits $\mathrm{CoCl} 2$-induced neurotoxicity through enhancement of Nrf2/GCLc/GSH and suppression of

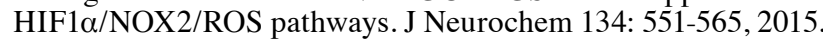

39. Wu X, Zhang F, Xiong X, Lu C, Lian N, Lu Y and Zheng S: Tetramethylpyrazine reduces inflammation in liver fibrosis and inhibits inflammatory cytokine expression in hepatic stellate cells by modulating NLRP3 inflammasome pathway. IUBMB Life 67: 312-321, 2015.

40. Zhao H, Xu ML, Zhang Q, Guo ZH, Peng Y, Qu ZY and Li YN: Tetramethylpyrazine alleviated cytokine synthesis and dopamine deficit and improved motor dysfunction in the mice model of Parkinson's disease. Neurol Sci 35: 1963-1967, 2014.

41. Guo M, Liu Y and Shi D: Cardiovascular actions and therapeutic potential of tetramethylpyrazine (Active Component Isolated from Rhizoma Chuanxiong): Roles and mechanisms. Biomed Res Int 2016: 2430329, 2016.

42. Hu JZ, Wang XK, Cao Y, Li DZ, Wu TD, Zhang T, Xu DQ and Lu HB: Tetramethylpyrazine facilitates functional recovery after spinal cord injury by inhibiting MMP2, MMP9, and vascular endothelial cell apoptosis. Curr Neurovasc Res 14: 110-116, 2017.

43. Bi L, Yan X, Chen W, Gao J, Qian Land Qiu S: Antihepatocellular carcinoma potential of tetramethylpyrazine induces cell cycle modulation and mitochondrial-dependent apoptosis: Regulation of p53 signaling pathway in HepG2 cells in vitro. Integr Cancer Ther 15: 226-236, 2016.

44. Lin KH, Kuo WW, Jiang AZ, Pai P, Lin JY, Chen WK, Day CH, Shen CY, Padma VV and Huang CY: Tetramethylpyrazine ameliorated hypoxia-induced myocardial cell apoptosis via HIF-1 $\alpha$ JNK/p38 and IGFBP3/BNIP3 inhibition to upregulate PI3K/Akt survival signaling. Cell Physiol Biochem 36: 334-344, 2015.

45. Fang Y, Chu L, Li L, Wang J, Yang Y, Gu J and Zhang J: Tetramethylpyrazine protects bone marrow-derived mesenchymal stem cells against hydrogen peroxide-induced apoptosis through PI3K/Akt and ERK1/2 pathways. Biol Pharm Bull 40: 2146-2152, 2017.

46. Wang Y, Yu T, Jin H, Zhao C and Wang Y: Knockdown MiR-302b alleviates LPS-induced injury by targeting smad3 in C28/I2 chondrocytic cells. Cell Physiol Biochem 45: 733-743, 2018.

This work is licensed under a Creative Commons Attribution-NonCommercial-NoDerivatives 4.0 International (CC BY-NC-ND 4.0) License. 